\title{
PRODUCCIÓN DE BLOQUES DE AGAROSA PARA VISUALIZACIÓN DE HONGOS
}

Marcela Gómez Garzón*, Tatiana Munar Cristancho**, Camila Suarez Martínez**, Jeannette León Enciso***, Alex Alexis Flórez****

\section{Resumen}

Objetivo: establecer un protocolo para la obtención de bloques de hongos utilizando agarosa como matriz. Métodos: los hongos se incluyeron en agarosa, el proceso se estandarizó y se probaron los protocolos en horno microondas, convencional y en el procesador automático para la obtención de láminas siguiendo la técnica histológica usual. Conclusiones: el protocolo del procesador para obtener múltiples láminas es reproducible y las preparaciones permitieron la visualización fácil de los hongos con coloraciones de H\&E y Gomori.

Palabras clave: técnica bloques celulares de agarosa, hongos, hematoxilina-eosina, Gomori.

Abreviaturas: H\&E, hematoxilina-eosina.

\section{AGAROSE BLOCK PREPARATION FOR FUNGI VISUALIZATION}

\section{Abstract}

Objective: To establish a protocol to obtain fungi blocks in an agarose matrix. Methods: fungi were embedded in agarose, the process was standardized and protocols were tested using a microwave oven, a conventional oven and an automated processor to obtain slides following the usual histological technique. Conclusions: the multiple slides processor protocol is reproducible and preparations allowed easy visualization of fungi with $\mathrm{H} \& \mathrm{E}$ and Gomori stains.

Key words: agarose cell block technique, fungi, hematoxylin and eosin, Gomori.

Fecha recibido: mayo 2 de 2013 - Fecha aceptado: julio 8 de 2013

* Magister Microbiología. Profesor Asociado, Fundación Universitaria Ciencias de la Salud. Bogotá DC, Colombia.

** Estudiante de la Facultad de Citohistología, Fundación Universitaria Ciencias de la Salud. Bogotá DC, Colombia.
*** Citohistóloga. Profesor Asistente, Fundación Universitaria Ciencias de la Salud. Bogotá DC, Colombia.

*****itohistólogo. Instructor Asistente, Fundación Universitaria Ciencias de la Salud. Bogotá DC, Colombia. 


\section{Introduc ción}

En nuestro medio la utilización de bloques celulares en citologías no ginecológicas es reducida. En 1920, Hayes Martin y Edward Ellis usaron agujas gruesas calibre 16 para obtener un aspirado de tumores palpables de mama y ganglios linfáticos. Con ella se preparaban extendidos gruesos que eran coloreados con H\&E y los fragmentos tisulares residuales llamados "coágulos" eran procesados como biopsias. En 1968 la técnica de la citología por aspiración fue modificada con el uso de agujas finas de calibre 22 por Soderstromm, Franzen y Zajicek. Desde entonces, la técnica es muy empleada por ser mínimamente invasiva y con el líquido obtenido se realizan láminas que serán coloreadas para realizar el diagnóstico, aunque la concentración de células sea baja. ${ }^{1}$

Diferentes estrategias se han implementado para preparar varias láminas a partir de una muestra escasa, como son las técnicas de monocapa y los bloques celulares. Las preparaciones monocapa con Cytospin o los nuevos sistemas automatizados como ThinPrep y AutoCyte permiten obtener entre tres y cinco láminas por muestra. La técnica de bloques en los cuales las muestras celulares son embebidas en parafina generan entre 20 y 50 cortes. ${ }^{2} \mathrm{Al}$ tener un buen número de láminas aumenta la posibilidad de realizar múltiples estudios inmunocitoquímicos, hibridación in situ por fluorescencia (FISH) o PCR, que permiten correlacionar cambios moleculares y clinicopatológicos en tumores. ${ }^{3,4}$

Las micosis invasivas se diagnostican en muestras citológicas de acuerdo con las características morfológicas que se observan con coloraciones de H\&E, Papanicolaou o Gomori en cortes histológicos de tejidos. ${ }^{5}$ La visualización de hifas o levaduras depende de la concentración del hongo en la muestra. Los grupos de investigación Célula \& Tejido y Grimic (infectología y microbiología clínica) estandarizaron la metodología para trabajar muestras líquidas que contienen hongos en bloques celulares utilizando agarosa como matriz. Se establecieron los protocolos para concentrar los hongos, los tiempos de fijadores que deben emplearse y las técnicas para embeber las células fúngicas obtenidas.

\section{Métodos}

Para producir los bloques de agarosa en el laboratorio de técnica histológica de la Fundación Universitaria de Ciencias de la Salud, se realizaron cultivos de los hongos Aspergillus spp, Fusarium spp, Scedosporium apiospermun, Acremonium spp y Candida albicans en medio RMPI-1640 suplementado. Se trabajó el hongo a baja y alta concentración mediante centrifugación a $5.000 \mathrm{rpm}$ durante cinco a diez minutos. Las concentraciones de agarosa utilizadas fueron $2 \%, 3 \%$ y $4 \%$. Se estableció la proporción de hongo en RMPI (1, 0,8 y $0,5 \mathrm{ml})$ y de agarosa fundida a $56^{\circ} \mathrm{C}(1,1,3$ y 1,5 $\mathrm{ml})$ para obtener bloques que salían completos con el perfilador y se podían cortar.

El procesamiento de los bloques de agarosa se realizó siguiendo los protocolos del laboratorio de técnica histológica y constó de las cuatro etapas: deshidratación, aclaración, impregnación en parafina y la inclusión de los bloques de agarosa. Se probaron los protocolos en horno microondas, convencional y en el procesador (Tabla 1). La selección del mejor protocolo se basó en la facilidad para realizar los cortes de cinco micras y la detección de los hongos con H\&E y Gomori.

\section{Resultados}

Se determinó que para producir los bloques de agarosa se requieren $0,5 \mathrm{ml}$ del hongo en alta concentración en RMPI y $1,5 \mathrm{ml}$ de agarosa al $2 \%$. Los protocolos horno microondas, convencional y procesador se evaluaron de acuerdo con la calidad del bloque para cortado y la capacidad de detección del hongo al microscopio. Los bloques obtenidos en el protocolo horno microondas presentaron consistencia blanda, las secciones quedaban pegadas a la cuchilla del micrótomo y se destruían, se lograron hacer pocas láminas que al ser analizadas al microscopio con H\&E mostraron la generación de artificios que no permitieron la detección de los hongos; las secciones coloreadas con Gomori se destruyeron al ser sometidas al ácido crómico (Figura 1). La consistencia de los bloques en el protocolo de horno fue adecuada, los cortes se realizaron con facilidad y se observó baja concentración de los hongos en las dos coloraciones (Figura 1). La calidad de los bloques en el protocolo del procesador fue adecuada, los cor- 


\section{Tabla I.Procedimientos de los protocolos}

\begin{tabular}{l|l}
$\begin{array}{l}\text { Protocolo: horno } \\
\text { microondas }\end{array}$ & $\begin{array}{l}\text { Mezclar I ml de cultivo de hongo con I ml de agarosa. } \\
\text { Solidificar la agarosa a temperatura ambiente. } \\
\text { Fijar en formol salino al I0\% por } 24 \text { horas. } \\
\text { Deshidratar en horno microondas el bloque de agarosa en etanol } 50 \%, 70 \%, 80 \%, 95 \%, y \text { tres veces al I00\%, cinco } \\
\text { minutos para cada paso. } \\
\text { Aclarar en xilol dos veces en horno microondas, cinco minutos para cada paso. } \\
\text { Infíltrar en el bloque de parafina líquida a } 64^{\circ} \mathrm{C}, \text { diez minutos dos veces. }\end{array}$ \\
\hline $\begin{array}{l}\text { Protocolo: horno } \\
\text { convencional }\end{array}$ & $\begin{array}{l}\text { Mezclar I ml de cultivo de hongo con I ml de agarosa. } \\
\text { Solidificar la agarosa a temperatura ambiente. } \\
\text { Fijar en formol salino al I0\% por } 24 \text { horas. } \\
\text { Deshidratar en horno el bloque de agarosa en etanol } 50 \%, 70 \%, 80 \%, 95 \% \text { durante } 30 \text { minutos y tres veces al I00\% } \\
\text { durante I6 minutos. } \\
\text { Aclarar en xilol tres veces, en horno, I5 minutos para cada paso. } \\
\text { Infiltrar en el bloque de parafina líquida a } 64^{\circ} \mathrm{C}, \text { una hora dos veces. }\end{array}$ \\
\hline $\begin{array}{l}\text { Protocolo: } \\
\text { procesador }\end{array}$ & $\begin{array}{l}\text { Mezclar } 0,5 \mathrm{ml} \text { de cultivo de hongo con I,5 ml de agarosa. } \\
\text { Solidificar la agarosa a temperatura ambiente. } \\
\text { Fijar en formol salino al I0\% por } 24 \text { horas. } \\
\text { Deshidratar en procesador el bloque de agarosa en etanol } 50 \%, 70 \%, 80 \%, 95 \% \text { durante } 30 \text { minutos y tres veces al I00\% } \\
\text { durante una hora. } \\
\text { Aclarar en xilol tres veces en procesador, una hora para cada paso. } \\
\text { Infiltrar en el bloque de parafina líquida a } 64^{\circ} \mathrm{C}, \text { una hora dos veces. }\end{array}$ \\
\hline
\end{tabular}

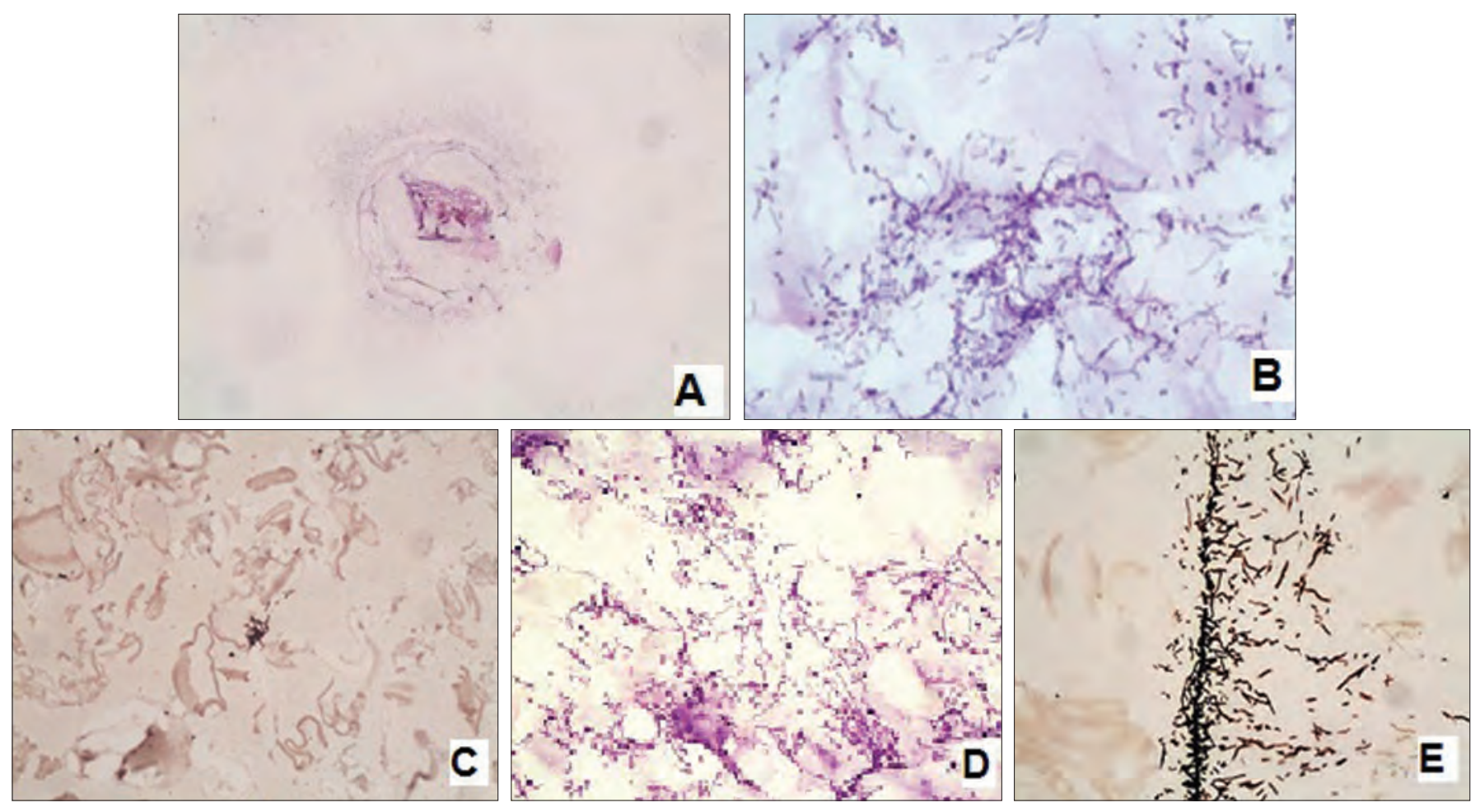

Figura I. Cortes de bloques de agarosa. A: protocolo horno microondas coloración H\&E I0x. B: protocolo horno convencional coloración H\&E I0x. C: protocolo horno convencional coloración Gomori 10x. D: protocolo procesador H\&E I0x. E: protocolo procesador coloración Gomori I0x. 
tes se realizaron sin problema y la concentración del hongo era apropiada para la rápida visualización de las estructuras fúngicas de los cinco tipo de hongos utilizados (Figura 2).

\section{Disc usión}

El método de inclusión en agarosa se utilizó para la producción de bloques de células micóticas. Para los bloques de tejidos se utiliza de rutina parafina, compuesto no miscible con agua ${ }^{6}$, por esta razón no se puede utilizar como matriz de muestras líquidas, como las empleadas en nuestro caso, cultivos líquidos de hongos.

La elección del fijador depende de las características que se desean estudiar, por ejemplo estructuras celulares, actividad enzimática o diagnósticos moleculares. La selección del formol salino se basó en el estudio comparativo de Nietner, al establecer que con este la morfología general y la detección de diferentes proteínas por inmunohistoquímica era mejor que con alcohol formol acido (AFA), PAXgene ${ }^{\circledR}$, HOPE® y combinación de AFA o formol con tratamientos de ultrasonidos. ${ }^{7}$ El Colegio Americano de Patología ha descartado el uso de fijadores no basados en formol y/o metodologías alternas, de acuerdo con las recomendaciones establecidas por un comité encargado de la estandarización de la técnica de inmunohistoquímica para el diagnóstico citológico. ${ }^{8}$

La utilización de horno microondas se ha aplicado desde 1970 para estudios de microscopia electrónica, hibridación in situ y PCR. El procedimiento histológico se realiza en un día y ha permitido reducir en forma considerable los tiempos de deshidratación y aclaramiento de los bloques para generar resultados rápidos. ${ }^{9}$ Nosotros observamos la reducción de tiempo pero la calidad de los bloques de agarosa obtenidos con el protocolo horno microondas era inadecuada. Los cortes en el micrótomo eran difíciles y las secciones obtenidas no permanecían adheridas a las láminas durante los procesos de coloración. A pesar de que se ha recomendado la implementación del horno microondas en cámara de vacío, bajo controles de temperatura y tiempo con resultados superiores a los obtenidos en el método convencional, aún no se ha establecido el efecto del proceso sobre los tejidos y los cambios que se producen en proteínas. ${ }^{10}$

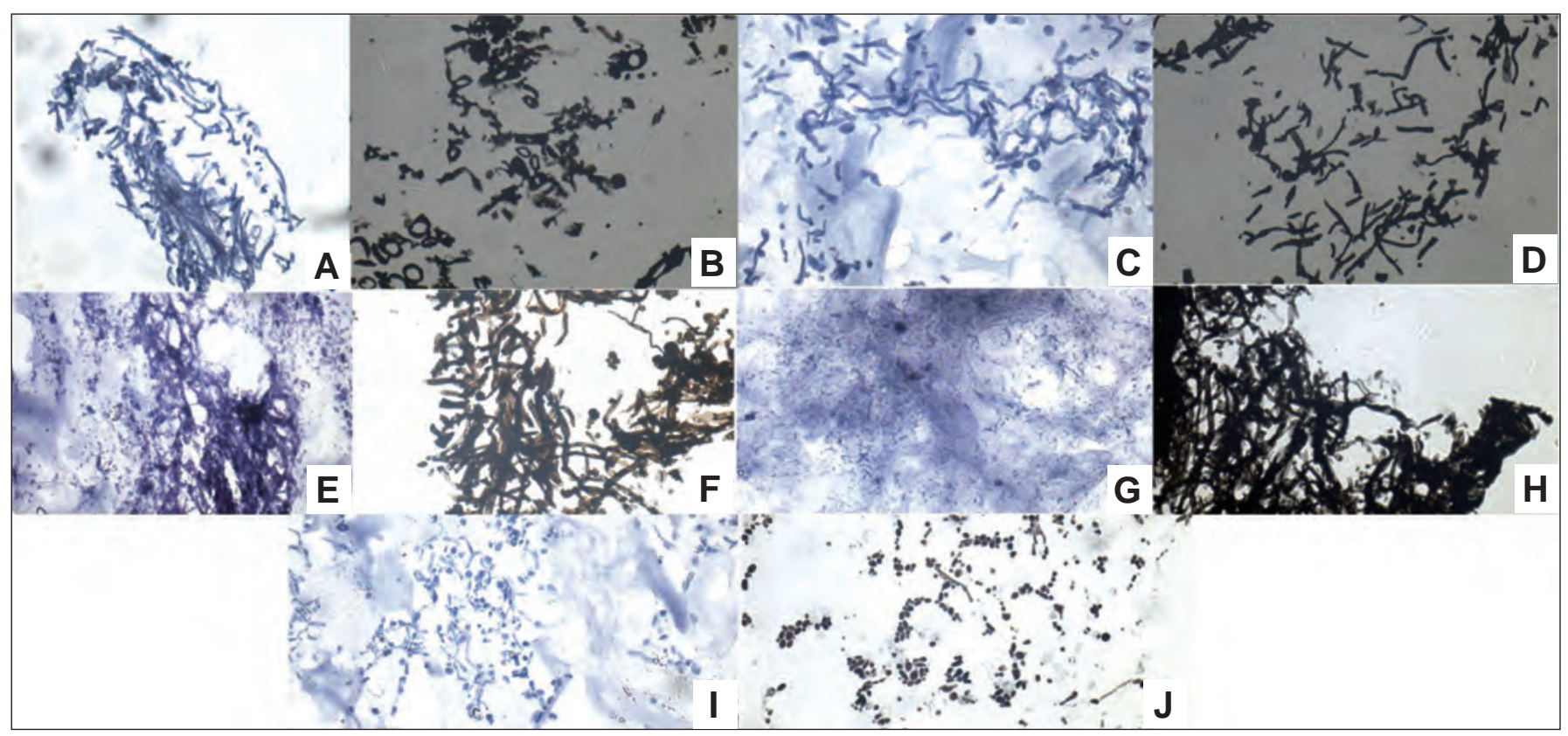

Figura 2. Cortes de bloques de agarosa con protocolo procesador. A: Aspegillus sp. H\&E 40x. B: Aspegillus sp. Gomori 40x. C: Fusarium sp. H\&E 40x. D: Fusarium sp. Gomori 40x. E: Acremonium sp. H\&E 40x. F: Acremonium sp. Gomori 40x. G: Scedosporium sp. H\&E 40x. H: Scedosporium sp. Gomori 40x. I: Candida albicans H\&E 40x. J: Candida albicans Gomori 40x. 
La agarosa es una matriz gelatinosa que le confiere al hongo una mayor protección de los factores físicos y químicos a los cuales se someten las muestras durante el proceso histológico. Las biopsias de tejidos se tratan con diferentes químicos para deshidratación, aclaración e impregnación, que se puede llevar a cabo en un horno microondas o en uno con temperatura por encima del ambiente, con el fin de lograr una mejor penetración de los reactivos en los tejidos. Al ser la agarosa un medio sensible a altas temperaturas, las muestras fueron probadas en el procesador de tejidos automático el cual utiliza los mismos reactivos químicos, pero estos actúan a temperatura ambiente, excepto la parafina, lo que hace que el proceso dure doce horas pero con una eficacia mayor gracias a la temperatura con la que se lleva a cabo el proceso.

Las técnicas de bloques celulares se usan en estudios citológicos de muestras de pleura, líquido peritoneal y lavado bronquial para diagnóstico de cáncer. ${ }^{11}$ Los bloques de agarosa se han empleado en el área de odontología en estudios de placa subgingival con Candida albicans ${ }^{12}$ y en veterinaria para el diagnóstico de osteomielitis por Aspergillus spp ${ }^{13}$ y diferentes tipos de tumores mamarios en caninos. ${ }^{14}$ Establecimos que el protocolo realizado en el procesador es reproducible, se obtienen secciones íntegras y se mantiene la estructura de los hongos, por estas razones puede usarse en muestras de hongos invasivos.

\section{Conclusiones}

La utilización de agarosa como matriz para muestras líquidas es aplicable para la producción de bloques celulares. El protocolo del procesador para obtener múltiples láminas es reproducible y las láminas permitieron la visualización fácil de los hongos con las coloraciones de H\&E y Gomori.

\section{Referencias}

1. Bravo Garcia M. Manual de técnicas y procedimientos histopatologicos. Mexico: Universidad Michoacana De San Nicolas De Hidalgo; 2011

2. Kerstens HM, Robben JC, Poddighe PJ, Melchers WJ, Boonstra H, de Wilde PC, et al. AgarCyto: a novel cell-processing method for multiple molecular diagnostic analyses of the uterine cervix. J Histochem Cytochem. 2000 May;48(5):709-18

3. Khan S, Omar T, Michelow P. Effectiveness of the cell block technique in diagnostic cytopathology. J Cytol. 2012 Jul; 29(3):177-82.

4. Nocito A, Kononen J, Kallioniemi OP, Sauter G. Tissue microarrays (TMAs) for high-throughput molecular pathology research. Int J Cancer. 2001 Oct 1 94(1):1-5.

5. Powers CN. Diagnosis of infectious diseases: a cytopathologist's perspective Clin Microbiol Rev. 1998 Apr; 11(2):341-65

6. Molist P, Pombal M, Megias M. Atlas de histología vegetal y animal [monografía en Internet]. Vigo (Pontevedra, España): Universidad de Vigo; 2008 [citado 23 Sep. 2013]. Disponible en: http://webs.uvigo.es/mmegias/inicio.html.

7. Nietner T, Jarutat T, Mertens A. Systematic comparison of tissue fixation with alternative fixatives to conventional tissue fixation with buffered formalin in a xenograft-based model. Virchows Archiv. 2012;461(3):259-69.

8. Goldstein NS, Hewitt SM, Taylor CR, Yaziji H, Hicks DG. Recommendations for improved standardization of immunohistochemistry. Appl Immunohistochem Mol Morphol. 2007 Jun; 15(2):124-33.

9. Emerson LL, Tripp SR, Baird BC, Layfield LJ, Rohr LR. A comparison of immunohistochemical stain quality in conventional and rapid microwave processed tissues. Am J Clin Pathol. 2006 Feb;125(2):176-83.

10. Mathai AM, Naik R, Pai MR, Rai S, Baliga P. Microwave histoprocessing versus conventional histoprocessing. Indian J Pathol Microbiol. 2008 Jan-Mar; 51(1):12-6.

11. Nigro K, Tynski Z, Wasman J, Abdul-Karim F, Wang N. Comparison of cell block preparation methods for nongynecologic ThinPrep specimens. Diagn Cytopathol. 2007 Oct;35(10):640-3.

12. Kavanagh K, Richardson M, Rautemaa R, Hietanen J. Medical Mycology. Cellular and Molecular Techniques. New York : John Wiley; 2007.

13. Zanoni DS, Grandi F, Cagnini DQ, Bosco SMG, Rocha NS. Agarose cell block technique as a complementary method in the diagnosis of fungal osteomyelitis in a dog. . Open Vet J. 2012;2:19-22.

14. Zanoni DS, Kleeb SR, Xavier JG. Emprego do cell block de agarose como método complementar no diagnóstico citológico de tumores mamários caninos. Ciênc. Rural. 2013;43(3):489-95. 